\title{
Formulation and pharmacopoeial quality evaluation of ketorolac tromethamine IR tablet and comparison with marketed product
}

\author{
Aysha Akter Shetu 1 , Suriya Sharmin², Satyajit Roy Rony ${ }^{2}$, Fatema Moni², Purabi Rani Samaddar ${ }^{1}$, Md. Hossain Sohrab ${ }^{2 *}$ \\ ${ }^{1}$ Department of Chemistry, Eden Mohila College, Dhaka, Bangladesh. \\ ${ }^{2}$ Pharmaceutical Sciences Research Division, BCSIR Laboratories, Dhaka, Bangladesh.
}

\section{ARTICLE INFO \\ Received on: 20/11/2018 \\ Accepted on: 26/03/2019 \\ Available online: 08/05/2019}

Key words:

Ketorolac tromethamine, direct compression, immediate release, quality evaluation, pharmaceutical equivalency, UV-Vis spectroscopy.

\begin{abstract}
This study describes the formulation of immediate release Ketorolac tromethamine (KT) 10-mg tablet by direct compression method; evaluation of their compliance to various Pharmacopoeial quality parameters, i.e., weight variation, friability, hardness, thickness, moisture content, disintegration, assay, and dissolution; and their comparison with marketed brands for determination of pharmaceutical equivalency. Five formulations of KT were prepared (coded as FKT1, FKT2, FKT3, FKT4, and FKT5) by direct compression method using different superdisintegrants. Micrometric properties of the mixtures of the drug and the excipients prepared for formulation were evaluated. Quality evaluation of the five different formulations and randomly selected four different brands of KT 10-mg tablets purchased from the local market (coded as LKT1, MKT2, MKT3, and SKT4) were performed according to Pharmacopoeia. The results were obtained by UV-Vis spectrophotometer and all the dissolution profiles were characterized by the zeroorder kinetics. All the brands of KT and developed formulations met the official specification except SKT4 which showed excessive moisture content of $7.18 \%$. None of the tested brands of KT were found to be pharmaceutically equivalent, whereas two developed formulation were pharmaceutically equivalent with the in house benchmark (MKT2) from which their interchangeability can be suggested.
\end{abstract}

\section{INTRODUCTION}

Ketorolac tromethamine is a non-steroidal antiinflammatory drug having potent analgesic activity chemically which is 2-amino-2-(hydroxymethyl) propane-1,3-diol; 5-benzoyl2,3-dihydro-1H-pyrrolizine-1-carboxylic acid (Fig. 1). It is a nonselective Cyclooxygenase (COX) inhibitor acting through the inhibition of prostaglandin synthesis by competitively blocking the enzyme COX (Banker and Anderson, 2009). Ketorolac is a safe and effective analgesic agent which can be administered intramuscularly or orally for the short-term management of acute postoperative pain, pain associated with rheumatoid or osteoarthritis, or dental pain for its low cost and safety. Ketorolac tromethamine (KT) has a short plasma half-life of 4-6 hours requiring its frequent administration rate. This may lead to gastric

${ }^{*}$ Corresponding Author

Md. Hossain Sohrab, Pharmaceutical Sciences Research Division, BCSIR Laboratories, Dhaka,Bangladesh.E-mail:mhsohrab@bcsir.gov.bd ulceration, bleeding, and other gastric complications in patients having a history of peptic ulcer disease or gastrointestinal bleeding or in geriatric patients for whom the treatment plan should be designed with much precaution (Chopra et al., 2008; Mohamed et al., 2015; Ong et al., 2007).

Several brands of KT tablets are available in Bangladesh which is most commonly used as analgesic to relief severe pain. The formulation properties and manufacturing methods play the key role on the quality of pharmaceutical dosage form; hence, it is usual that the quality of dosage form may differ with different available brands (The Pharmaceutical Codex, 1994). Based on the dose and the physical properties of drugs such as compressibility and flow properties of the blend/physical mixtures of drug and excipients, there are three methods of tablet manufacturing (Halbert, 1993). Direct compression is one of the processes of choice for its advantages over the other manufacturing methods for tablets, such as wet granulation for its high efficiency, reduced cycle time, less contact of moisture for thermolabile and moisture sensitive product, etc. (Beyer et al., 2001; Yasmeen et al., 2005; Zhang et al., 2003). Tablets manufactured by direct compression 


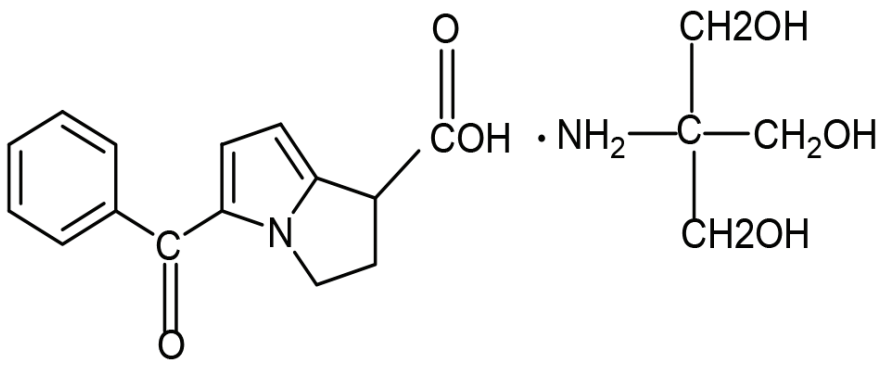

Figure 1. Chemical structure of Ketorolac tromethamine.

method have less chance of microbial contamination than those prepared by the wet granulation method and disintegrate into particle form of active pharmaceutical ingredients (APIs) instead of granules that directly come into contact with the dissolution media, hence show comparatively faster dissolution rate (Gohel, 2005; Ibrahim and Olurinola, 1991).

In the present research work, cost effective, immediate release KT 10-mg tablets by direct compression method using different superdisintegratants, such as Crosscarmellose sodium, Microcrystalline cellulose, and Maize starch, have been developed and evaluated their compliance to various pharmacopoeial quality control parameters and made their comparison with marketed brands in terms of quality control parameters. In vitro pharmaceutical equivalency was also determined for both developed and marketed tablets. The purpose is also to reduce the disintegration time of the tablets to improve dissolution pattern. Quality of developed formulations and marketed brands were evaluated by determining physico-chemical characteristics (weight variation, friability, hardness, thickness, moisture content, disintegration, assay, and dissolution) of product following standard methods given in United States Pharmacopoeia (USP), British Pharmacopeia (BP), etc. Comparative study of developed formulation with marketed product (four brands coded as LKT1, MKT2, MKT3, and SKT4) was conducted based on physicochemical properties and in vitro determination of pharmaceutical equivalency considering MKT2 as benchmark for high drug release.

\section{MATERIALS AND METHODS}

\section{Materials}

API KT was kindly gifted by Beximco Pharmaceuticals Ltd. Four different commercial brands of Bangladesh containing $10 \mathrm{mg}$ of KT were purchased from retail pharmacy store and represented here by LKT1, MKT2, MKT3, and SKT4. Brands were randomly selected on the basis of company market share where in codes L stands for large market share; $M$ stands for medium market share, and $S$ stands for small market share. Microcrystalline Cellulose (Avicel PH-101), Crosscarmellose Sodium, Lactose, Maize starch, Talc, and Magnesium stearate were used as direct compression excipients. All other chemicals and reagents were purchased from Active Fine Chemicals, Ltd.

\section{Instrumentation}

UV-Vis spectrophotometer (Analytik Jena, Germany); Digital pH meter (Hatch Company, USA); Electronic hardness tester (Copley, England); Electronic friability tester (Copley, England); Tablet thickness tester (Mitutoyo, Japan); Tablet disintegration tester (Copley, England); Tablet dissolution tester (Copley, England); Scientech electronic balance (USA); Moister analyzer (Precisa, Switzerland); Sonicator (Wisd, Germany); Water Distillation machine (Merit w4000, UK) were used in this study.

\section{Preparation of granules}

All the ingredients were dispensed as per the batch size of Table 1 and shifted through 30 mesh sieve separately except Magnesium stearate and Talc. These above ingredients were mixed at geometric ratio and blended for 15 minutes in a large size poly bag using tumbling action. Then Magnesium stearate and Talc were mixed with the above blend by shifting through 30 mesh sieve and blended for further 3 minutes. Finally, blend was compressed using the single punch tablet machine (TSD-5 China).

\section{Preformulation studies}

Preformulation studies are primarily done to investigate the physical properties of the powder mixture and to establish its compatibility with other excipients.

\section{Bulk density}

Bulk density is calculated by the following formula (USP 29-NF-24, 2006a):

Bulk density $=$ Weight of granules/Bulk volume

Tapped density

Tapped density is the ratio of total mass of powder to the tapped volume of the powder (USP 29-NF-24, 2006a), which can be determined by the following formula:

Tapped Density $=$ Mass of the powder/Tapped volume of the powder

\section{Angle of repose $(\theta)$}

Angle of repose, the measurement of friction forces in a loose powder, is defined as maximum angle possible between the surface of the pile of powder and horizontal plane (USP 29-NF$24,2006 \mathrm{~b})$. It is defined as maximum angle possible between the surface of the pile of powder and the horizontal plane. To measure the angle of repose, the powder was allowed to flow freely through a funnel with height adjusted such a way that the tip of the funnel

Table 1. Formulation of Ketorolac tromethamine immediate release tablet based on four different superdisintegrants.

\begin{tabular}{lccccc}
\hline \multirow{2}{*}{ Ingredients (mg/tablet) } & \multicolumn{5}{c}{ Batch Code } \\
\cline { 2 - 6 } & FK1 & FK2 & FK3 & FK4 & FK5 \\
\hline Ketorolac trimethamine & 10 & 10 & 10 & 10 & 10 \\
Crospovidone & 40 & 60 & - & - & - \\
Crosscarmellose sodium & - & - & 6.40 & 6 & - \\
Maize starch & - & - & - & - & 10.17 \\
Microcrystalline cellulose & 78 & 58 & 109.70 & 59.2 & 50.85 \\
Lactose & - & - & - & 52.8 & 50.85 \\
Talc & - & - & 1.50 & 1.50 & 8.13 \\
Magnesium Stearate & 2 & 2 & 2.50 & 2.50 & - \\
Quantity per Tablet (mg) & 130 & 130 & 129.60 & 132 & 130 \\
\hline
\end{tabular}


just touches the apex of the powder heap. Angle of repose can be calculated using following equation:

$$
\tan (\theta)=h / r
$$$$
(\theta)=\tan ^{-1}(h / r)
$$

where $\theta$ is the angle of repose, $h$ is the height in $\mathrm{cm}$, and $r$ is the radius in $\mathrm{cm}$.

\section{Compressibility index and Hausner's ratio}

The compressibility index (Carr's Index) and Hausner's ratio (USP 29-NF-24, 2006a) of all the prepared powder blends were determined from their bulk density and tapped density values by following equation:

Compressibility index $=\left|\frac{\text { Tapped Density }- \text { Bulk Density }}{\text { Tapped Density }}\right| \times 100$

Hausner's ratio was calculated as follows:

Hausner's ratio $=$ Tapped density/Bulk density

\section{Quality evaluation of tablets}

Weight variation

The weight of 20 tablets was determined individually using an electronic digital balance to evaluate weight variation among tablets. The average tablet weight and standard deviation were calculated and compared with the permissible limits (BP, 2012c).

$\%$ weight variation $=\frac{\text { Initial Tablet } \mathrm{Wt}-\text { Final Tablet } \mathrm{Wt}}{\text { Final Tablet } \mathrm{Wt}} \times 100$

\section{Hardness test}

Hardness tester was used to measure the hardness of the tablet. Ten tablets from each marketed brand and formulated preparation were randomly selected and their hardness was determined (BP, 2012e).

\section{Thickness test}

The crown thickness of individual tablets was measured with a Tablet thickness tester which is a type of a micrometer. Tablet thickness should be within the limit of $\pm 5 \%$ variation (Banker and Anderson, 2009).

\section{Friability test}

For friability testing, 10 randomly selected tablets from each marketed brands and formulated tablets were initially weighed and placed in a friabilator chamber. The friability testing machine was operated at $25 \mathrm{rpm}$ for 4 minutes (up to 100 revolutions). Thereafter, tablets were removed, dusted, and reweighed. The percent (\%) friability was calculated by using following formula (BP, 2012d):

$$
\% \text { Friability }=\frac{\text { Initial Tablet } \mathrm{Wt}-\text { Final Tablet } \mathrm{Wt}}{\text { Final Tablet } \mathrm{Wt}} \times 100
$$

\section{Loss on drying}

Loss on drying (LOD) is an expression of the moisture content of solid formulation on a wet-weight basis, which is calculated as follows (BP, 2012a):

$\% \mathrm{LOD}=$ wt of water in sample/total wt of wet sample $\times 100$

\section{Disintegration test}

A digital tablet disintegration test apparatus was used for the disintegration test. A $900-\mathrm{ml}$ beaker was filled with distilled water and maintained at $37^{\circ} \mathrm{C} \pm 0.5^{\circ} \mathrm{C}$. Six tablets from each brand and formulation were taken and placed in each of the cylindrical tubes of the basket and connected to the disintegration apparatus. To avoid the floating of tablets during upward and downward movement in water, discs were used. The time required to break each tablet into small particles and pass out through the mesh at the bottom of the tube is the disintegration time which was recorded (BP, 2012b).

\section{Determination of dissolution rate (Ketorolac tromethamine)}

The dissolution study of the formulated tablets and marketed brands was carried using USP standard dissolution apparatus II containing $600 \mathrm{ml}$ of distilled water as a dissolution medium (Paddle method). Samples $(10 \mathrm{ml})$ were collected at predetermined time intervals $(5,10,15,20,30$, and 45 minutes) and replaced with equal volume of fresh medium, filtered through $0.45-\mu \mathrm{m}$ Whatman No. 1 filter paper and analyzed with a UV visible spectrophotometer at $\lambda_{\max } 322 \mathrm{~nm}$. The percentage of cumulative drug release of each tablet from formulated tablets and marketed brands was determined using the linear regression equation of the calibration curve (Fig. 2; Table 2). A $20.30 \mathrm{mg}$ of standard KT was dissolved in $100 \mathrm{ml}$ of dissolution media to prepare the standard stock solution. 1, 2, 3, 4, and $5 \mathrm{ml}$ of this solution was diluted up to $50 \mathrm{ml}$ with the dissolution media to produce concentration of 4.06 , $8.12,12.18,16.24$, and $20.30 \mu \mathrm{g} / \mathrm{ml}$, respectively and absorbance of each sample was taken.

\section{Test for content (assay)}

From the stock solution of KT in methanol, a series of working solutions with concentrations of 4.06, 8.12, 12.18, 16.24, and $20.30 \mu \mathrm{g} / \mathrm{ml}$ were prepared in methanol to prepare a calibration curve measured at $322 \mathrm{~nm}$. The limit of detection (LOD) and limit of quantification (LOQ) values were determined from the standard deviation of the residual calculated from the regression equation of calibration graph as described by Shrivastava and Gupta (2011) (Fig. 2; Table 2) to ascertain that the concentration of solutions used to make calibration curve is greater than LOQ. Using this curve, the amount of KT in each brand and formulation were determined.

\section{Comparison of dissolution profiles}

To consider the two pharmaceutical products similar, two adjustment factors $\left(f_{1}\right.$ and $\left.f_{2}\right)$ comparing the dissolution profile of a pair of pharmaceutical products were applied to the dissolution data as a model independent approach. To ensure sameness of the curves, $f_{1}$ values should be close to 0 and $f_{2}$ values should be close to 100 . Generally, $f_{1}$ values up to $15(0-15)$ and $f_{2}$ values greater than $50(50-100)$ ascertain sameness or equivalence of the two curves (Apurba et al., 2011; Mubengayi et al., 2016).

$$
\begin{aligned}
& f_{1}=\left\{\left[\sum_{1}^{n}|R t-T t|\right] /\left[\sum_{1}^{n} R t\right]\right\} \times 100 \\
& f_{2}=50 \log \left\{\left[1+(1 / n) \sum_{1}^{n}(R t-T t)^{2}\right]^{-0.5} \times 100\right\}
\end{aligned}
$$




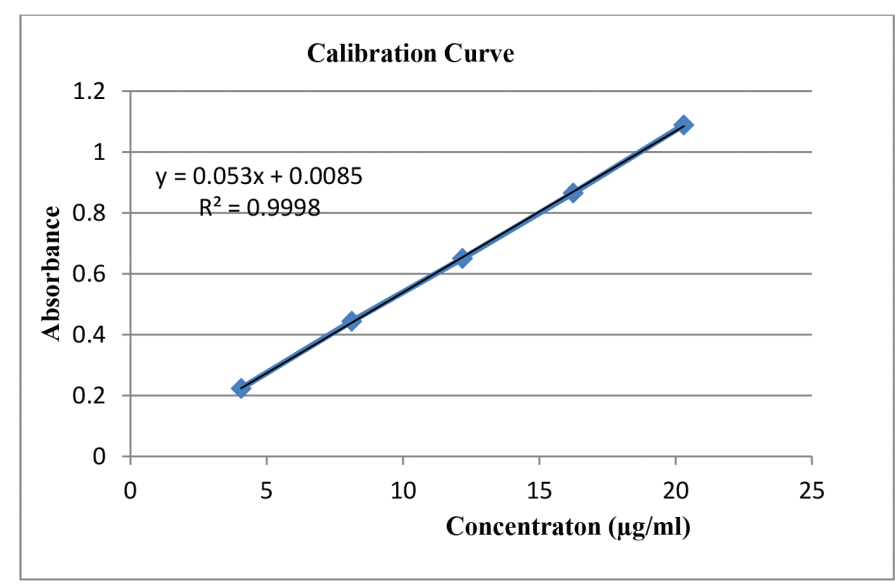

Figure 2. Calibration curve of Ketorolac tromethamine.

Table 2. Calculation of LOD and LOQ by estimation of $y$-residuals of regression line.

\begin{tabular}{ccc}
\hline Concentration & Absorbance & Squared $\boldsymbol{y}$-residuals \\
\hline 4.06 & 0.2233 & 0.000000 \\
8.12 & 0.4440 & 0.000032 \\
12.18 & 0.6500 & 0.000013 \\
16.24 & 0.8653 & 0.000012 \\
20.3 & 1.0889 & 0.000025 \\
Sum of the squared $y$-residuals & & 0.000082 \\
Standard deviation of $y$-residuals of regression lines & 0.004 \\
Slope of regression line & & 0.053 \\
Limit of detection (LOD) & & $0.23 \mu \mathrm{g} / \mathrm{ml}$ \\
Limit of quantification (LOQ) & & $0.75 \mu \mathrm{g} / \mathrm{ml}$ \\
\hline
\end{tabular}

where $n$ is the number of dissolution sample time points and $R_{t}$ and $T_{t}$ are the mean percent dissolution value at each time point $t$ for the reference products and test sample dissolution profile, respectively.

\section{Statistical analysis}

Single factor analysis of variance study was conducted for the developed formulations using Microsoft excel software to establish the significant effect of the variable, here superdisintegrant concentration on dissolution data. $p<0.05$ was considered significant and indicated main effects on optimizing formulations.

\section{RESULTS AND DISCUSSION}

KT 10-mg tablet was prepared by using direct compression method with the excipients tabulated in Table 1 by adjusting the concentration of super disintegrants, such as Crosscarmellose sodium, Crospovidone, Maize starch, and other ingredients. The study of pre-compression property was tabulated in Table 3. The Compressibility and Hausner's ratio of various blends were calculated by using bulk density and tapped density data. The compressibility index was found in the range $12.50 \%-18.52 \%$. The Hausner's ratio was found in the range 1.13-1.23 which suggests that all the prepared granules possess good flowability. Angle of repose was found in the range of $15^{\circ}$ $28.9^{\circ}$. From the compressibility index and angle of repose, results
Table 3. Flow properties of formulation (Ketorolac tromethamine).

\begin{tabular}{cccccc}
\hline $\begin{array}{c}\text { Batch } \\
\text { code }\end{array}$ & $\begin{array}{c}\text { Bulk } \\
\text { density(g/ml) }\end{array}$ & $\begin{array}{c}\text { Tapped } \\
\text { density }(\mathbf{g} / \mathbf{m l})\end{array}$ & $\begin{array}{c}\text { Carr's index } \\
(\%)\end{array}$ & $\begin{array}{c}\text { Hausner } \\
\text { ratio }\end{array}$ & $\begin{array}{c}\text { Angle of } \\
\text { repose }(\theta)\end{array}$ \\
\hline FKT1 & 0.33 & 0.38 & 15.38 & 1.15 & $16.87^{\circ}$ \\
FKT2 & 0.44 & 0.54 & 18.52 & 1.23 & $25.30^{\circ}$ \\
FKT3 & 0.42 & 0.48 & 12.50 & 1.14 & $28.90^{\circ}$ \\
FKT4 & 0.30 & 0.35 & 13.79 & 1.14 & $15.00^{\circ}$ \\
FKT5 & 0.29 & 0.33 & 13.27 & 1.13 & $20.90^{\circ}$ \\
\hline
\end{tabular}

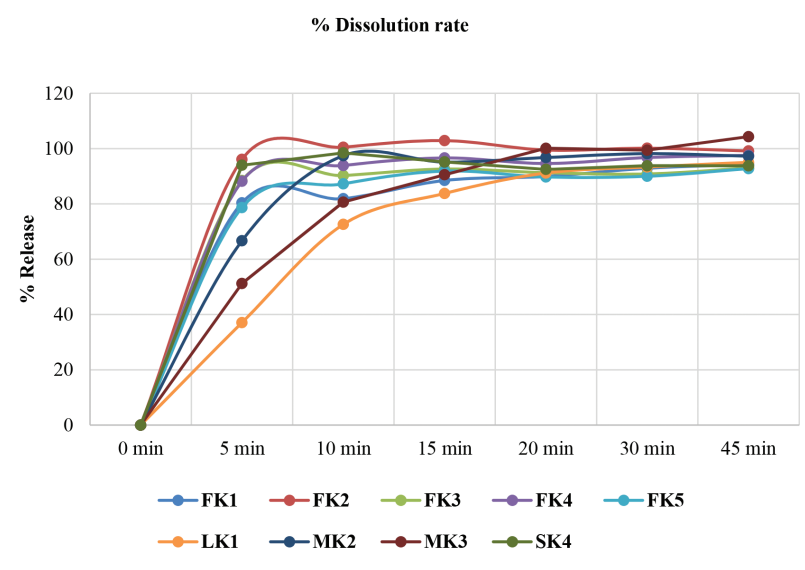

Figure 3. Percent release of ketorolac at different time interval of formulated and marketed tablets with standard deviation error bar.

formulation FK4 and FK5 were found to have excellent flow property, whereas formulation FK1 and FK3 possessed good flow property. The result of the dissolution study of all the formulated and marketed tablets was shown in Figure 3. With 50\% increase of Crosspovidone as superdisintegrant, the dissolution rate was increased from $84.10 \%$ to $96.09 \%$ at 5 minutes time interval with $p<0.05$, but formulation of FK2 showed fair flowability. Formulation FK3 with Crosscarmellose sodium showed good dissolution and flow property of granules. Replacing half of the filler Microcrystalline cellulose with lactose did not cause any significant change in the dissolution property $(p>0.5)$ or the flow property of granules. So, in FK5, only disintegrant was changed to maize starch, which resulted in a decrease in the dissolution pattern from $88 \%$ to $78 \%$ at 5 minutes time interval, which is a significant result with $p<0.05$. The moisture content was slightly increased for FK5. The post compression studies of formulated KT tablets are tabulated in Table 4 and marketed KT tablets are tabulated in Table 5. They reviled that all the quality parameters, such as friability, weight variation, hardness, disintegration time, assay, etc., are within the acceptance criteria limits for individual tests of marketed brands except SKT4 which showed higher moisture content. Difference $\left(f_{1}\right)$ and similarity $\left(f_{2}\right)$ tests were applied to the release rate to compare the dissolution profile. For KT tablet, brand MKT2 was considered as the benchmark for high dissolution rate. None of the three brands, namely, LKT1, MKT3, and SKT4 complies with the in-house reference standard MKT2 (Table 6) which may result from different excipients pattern of the formulations. Three developed formulations (FK1, FK4, and FK5) comply with the in-house reference standard MKT2 (Table 6). For 
Table 4. Evaluation of different formulations FKT1, FKT2, FKT3, FKT4, and FKT5.

\begin{tabular}{|c|c|c|c|c|c|c|c|}
\hline Parameters & FK1 & FK2 & FK3 & FK4 & FK5 & Standard specification & Remarks \\
\hline $\begin{array}{l}\text { Average weight } \\
\text { Weight variation (\%) }\end{array}$ & $\begin{array}{c}129.64 \\
(-) 2.19 \text { to }(+) 1.73\end{array}$ & $\begin{array}{c}130.26 \\
(-) 2.66 \text { to }(+) 1.48\end{array}$ & $\begin{array}{c}129.50 \\
(-) 2.04 \text { to }(+) 1.89\end{array}$ & $\begin{array}{c}129.76 \\
(-) 2.05 \text { to }(+) 1.64\end{array}$ & $\begin{array}{c}129.22 \\
(-) 1.16 \text { to }(+) 2.07\end{array}$ & $\begin{array}{l}\text { For } \leq 130 \mathrm{mg} \text { tablet, } \\
\text { accepted weight variation } \\
\text { range, } 10 \%\end{array}$ & Comply \\
\hline Hardness $(\mathrm{kg})$ mean $\pm \mathrm{SD}$ & $7.84 \pm 0.71$ & $7.37 \pm 0.95$ & $7.17 \pm 0.83$ & $7.42 \pm 0.43$ & $7.02 \pm 1.08$ & Force about $4 \mathrm{~kg}$ & Comply \\
\hline Friability (\%) & 0.01 & 0.08 & 0.03 & 0.04 & 0.01 & $0.5-1$ & Comply \\
\hline $\begin{array}{l}\text { Thickness (mm) Mean } \\
\pm \text { SD }\end{array}$ & $2.64 \pm 0.11$ & $2.85 \pm 0.11$ & $2.81 \pm 0.16$ & $3.05 \pm 0.08$ & $2.93 \pm 0.09$ & - & Comply \\
\hline Loss on Dying (\%) & 3.17 & 3.54 & 2.56 & 3.61 & 4.45 & $1.50-5$ & Comply \\
\hline Disintegration time & 58 seconds & 1 minute 5 seconds & $\begin{array}{l}1 \text { minute } 36 \\
\text { seconds }\end{array}$ & $\begin{array}{l}1 \text { minute } 45 \\
\text { seconds }\end{array}$ & $\begin{array}{l}1 \text { minute } 45 \\
\text { seconds }\end{array}$ & Within 30 minutes & Comply \\
\hline $\begin{array}{l}\text { Dissolution test ( } \% \text { drug } \\
\text { release) mean } \pm \text { SD }\end{array}$ & $94.28 \pm 1.14$ & $99.15 \pm 4.06$ & $93.01 \pm 3.51$ & $97.48 \pm 0.85$ & $92.64 \pm 2.95$ & After 45 minutes $>75 \%$ & Comply \\
\hline $\begin{array}{l}\text { Assay (milligram per } \\
\text { tablet) mean } \pm \mathrm{SD}\end{array}$ & $9.91 \pm 0.10$ & $9.55 \pm 0.23$ & $9.91 \pm 0.57$ & $10.35 \pm 0.37$ & $10.20 \pm 0.12$ & $9-11$ & Comply \\
\hline
\end{tabular}

Table 5. Evaluation of different brands LKT1, MKT2, MKT3, and SKT4.

\begin{tabular}{|c|c|c|c|c|c|c|}
\hline Parameters & LKT1 & MKT2 & MKT3 & SKT4 & $\begin{array}{l}\text { USP/BP } \\
\text { Specification }\end{array}$ & Remarks \\
\hline Average weight \pm SD & $173.60 \pm 1.37$ & $102.73 \pm 1.60$ & $140.32 \pm 4.03$ & $166.93 \pm 3.69$ & $\begin{array}{l}\text { For } \leq 130 \mathrm{mg} \text { and } \\
130-324 \mathrm{mg} \text { tablets }\end{array}$ & \\
\hline Weight variation (\%) & $(-) 1.32$ to $(+) 0.98$ & $(-) 3.34$ to $(+) 2.21$ & $(-) 5.78$ to $(+) 7.11$ & $(-) 4.39$ to $(+) 5.31$ & $\begin{array}{l}\text { accepted weight } \\
\text { variation, } 10 \% \text { and } \\
7.5 \% \text {, respectively }\end{array}$ & Comply \\
\hline $\begin{array}{l}\text { Hardness }(\mathrm{kg}) \\
\text { Mean } \pm \text { SD }\end{array}$ & $6.70 \pm 0.31$ & $8.08 \pm 0.60$ & $5.70 \pm 0.45$ & $4.02 \pm 0.71$ & Force about $4 \mathrm{~kg}$ & Comply \\
\hline Friability (\%) & 0.30 & 0.02 & 0.18 & 0.02 & $0.5-1$ & Comply \\
\hline $\begin{array}{l}\text { Thickness }(\mathrm{mm}) \\
\text { Mean } \pm \text { SD }\end{array}$ & $3.28 \pm 0.02$ & $3.26 \pm 0.02$ & $3.13 \pm 0.07$ & $3.86 \pm 0.08$ & - & Comply \\
\hline Loss on dying ( $\%)$ & $3.24 \%$ & $4.32 \%$ & $3.66 \%$ & $7.18 \%$ & $1.50-5$ & $\begin{array}{l}\text { SKT4 does not } \\
\text { comply }\end{array}$ \\
\hline Disintegration time & 6 minutes 0 seconds & 6 minutes 56 seconds & 7 minutes 45 seconds & 11 minutes 10 seconds & Within 30 minutes & Comply \\
\hline $\begin{array}{l}\text { Dissolution test } \\
(\% \text { drug release }) \\
\text { Mean } \pm \mathrm{SD}\end{array}$ & $95.04 \pm 1.94$ & $97.26 \pm 2.25$ & $104.34 \pm 3.45$ & $96.60 \pm 1.13$ & $\begin{array}{l}\text { After } 45 \text { minutes } \\
>75 \%\end{array}$ & Comply \\
\hline $\begin{array}{l}\text { Assay (mg per tablet) } \\
\text { mean } \pm \mathrm{SD}\end{array}$ & $10.31 \pm 0.18$ & $10.44 \pm 0.006$ & $10.89 \pm 0.72$ & $10.82 \pm 1.06$ & $9-11$ & Comply \\
\hline
\end{tabular}

Table 6. Comparative dissolution profile of formulated ketorolac tablets and different marketed brands.

\begin{tabular}{|c|c|c|c|c|c|c|c|c|}
\hline \multicolumn{2}{|c|}{ Time (minute) } & \multirow{2}{*}{$\frac{\mathbf{5}}{84.10}$} & \multirow{2}{*}{$\frac{10}{84.65}$} & \multirow{2}{*}{$\frac{15}{91.89}$} & \multirow{2}{*}{$\frac{\mathbf{2 0}}{92.79}$} & \multirow{2}{*}{$\frac{\mathbf{3 0}}{92.91}$} & \multirow{2}{*}{$\frac{\text { Difference factor }\left(f_{1}\right)}{8.77}$} & \multirow{2}{*}{$\frac{\text { Similarity factor }\left(f_{2}\right)}{51.37}$} \\
\hline Formulation & FK1 & & & & & & & \\
\hline \multirow{8}{*}{ Different brand } & FK2 & 96.09 & 100.50 & 102.59 & 99.48 & 100.16 & 9.25 & 44.88 \\
\hline & FK3 & 88.47 & 90.27 & 92.69 & 91.29 & 90.84 & 9.10 & 49.74 \\
\hline & FK4 & 88.19 & 93.97 & 96.62 & 94.90 & 96.79 & 5.93 & 52.98 \\
\hline & FK5 & 78.68 & 87.25 & 91.88 & 89.75 & 90.00 & 8.32 & 54.74 \\
\hline & LKT1 & 37.07 & 71.22 & 83.80 & 91.18 & 93.35 & 17.45 & 35.57 \\
\hline & MKT2 & 69.34 & 97.44 & 95.12 & 96.78 & 98.19 & \multicolumn{2}{|c|}{ In house bench mark } \\
\hline & MKT3 & 52.47 & 80.67 & 90.55 & 100.11 & 99.44 & 9.42 & 47.96 \\
\hline & SKT4 & 94.83 & 98.46 & 95.20 & 92.49 & 92.81 & 7.76 & 46.45 \\
\hline
\end{tabular}

higher moisture content of FK5, other two formulated products (FK1 and FK4) can be considered interchangeable with in-house reference standard (MKT2).

\section{CONCLUSION}

Five different formulations of Ketorolac tromethamine $10 \mathrm{mg}$ immediate release tablet have been developed by applying direct compression method successfully with accepted limit of quality control parameters among those, two developed formulated products (FK1 and FK4) are likely to perform similar with the in-house reference standard. FK4 can be considered as the best formulation with significant dissolution property $(p<$ 0.05 ) and physicochemical behavior in both granulation and postcompression stage. The developed formulations can be arranged 
in the order of acceptability as FK $4>$ FK $1>$ FK $3>$ FK $2>$ FK 5 . Therefore, it can be anticipated that two developed generics (FK1 and FK4) can be considered interchangeable and subjected for further in vivo and in vitro pharmacokinetic studies. None of the tested marketed brands (LK1, MK3, and SK4) showed $f_{1}$ and $f_{2}$ value within the accepted limit which emphasizes the need for Good Manufacturing Practices (GMP) application by the pharmaceutical company and a continuous market monitoring of pharmaceutical products to ensure their equivalence to the reference products.

\section{ACKNOWLEDGMENTS}

The authors would like to thank the Bangladesh Council of Scientific and Industrial Research (BCSIR) for funding this research. The authors also would like to thank the Beximco Pharmaceuticals Ltd., Bangladesh for the supply of standard of Ketorolac tromethamine.

\section{CONFLICT OF INTEREST}

Authors have no conflict of interest to declare.

\section{ETHICAL APPROVAL}

There is no study involving human participants or animal studies performed by any of the authors.

\section{FUNDING SOURCES} research

The authors received no external funding for this

\section{REFERENCES}

Apurba SA, Nazmul HK, Monjurul K, Nani GB, Khandoker SM, Jamaluddin ATM, Zakiur R. In vitro evaluation of the pharmaceutical equivalence of phenoxymethyl penicillin tablet formulations available in Bangladesh. J Pharm Res, 2011; 4(5):1445-7.

Banker GS, Anderson NR. Tablets. In: Lachman L, Lieberman HA, Kanig JL (eds.). The theory and practice of industrial pharmacy. 3rd edition, Lea and Febiger, Philadelphia, PA, pp. 296-300, 2009.

Beyer T, Day GM, Price SL. The prediction, morphology and mechanical properties of the polymorphs of Paracetamol. J Am Chem Soc, 2001; 123:5086-94.

British Pharmacopeia. H.M. Stationery office. Appendix IXE, London, UK, vol. 5, p. A285, 2012a.

British Pharmacopeia. H.M. Stationery office. Appendix XIIA, London, UK, vol. 5, p. A320, 2012b.

British Pharmacopeia. H.M. Stationery office. Appendix XIIC, London, UK, vol. 5, p. A341, 2012c.

British Pharmacopeia. H.M. Stationery office. Appendix XVIIG,

London, UK, vol. 5, p. A471, 2012 d.

British Pharmacopeia. H.M. Stationery office. Appendix XVIIH, London, UK, vol. 5, p. A472, 2012e.
Chopra D, Sinha VR, Singh M. Thermal and isothermal methods in development of sustained release dosage forms of Ketorolac Tromethamine. E-J Chem, 2008; 5(2):316-22.

Gohel MC. A review of co-processed directly compressible excipients. J Pharm Sci, 2005; 8(1):76-93.

Halbert GW. Pharmaceutical development. In: Griffin JP, Grady JO, Wells FO (eds.). The text book of pharmaceutical medicine. Greystone Books Ltd., Antrim, Northern Ireland, pp. 39-40, 1993.

Ibrahim YK, Olurinola PF. Comparative microbial contamination levels in wet granulation and direct compression methods of tablet production. Pharm Acta Helv, 1991; 66:293-301.

Mohamed MI, Soliman NA, Rahim SHAE, Development of a novel Ketorolac Tromethaminesublingual film. J Am Sci, 2015; 11(7):2737.

Mubengayi CK, Ramli Y, Routaboul C, Gilard V, Karbane ME, Cherrah Y, Martinao MM, Essasi EM. Quality evaluation of Diclofenacformulations manufactured in DR Congo. Pharm Anal Chem Open Access, 2016; 2:112

Ong CKS, Lirk P, Tan CH, Seymour RA. An evidence-based update on Nonsteroidal anti-inflammatory drugs. Clin Med Res, 2007; 5(1):19-34.

Shrivastava A, Gupta VB. Methods for the determination of limit of detection and limit of quantitation of the analytical methods. Chron Young Sci, 2011; 2:21-5.

The Pharmaceutical Codex. Principle and practice of pharmaceutics. 12th edition, Pharmaceutical Press, London, UK, pp. 987 92, 1994.

United States Pharmacopeia and National Formulary (USP 29NF 24). United States Pharmacopeia Convention, Rockville, MD, p. 2638 $2006 a$.

United States Pharmacopeia and National Formulary (USP 29NF 24). United States Pharmacopeia Convention, Rockville, MD, p. 3017, $2006 \mathrm{~b}$.

Yasmeen R, Shoaib MH, Khalid H. Comparative study of different formulations of Atenolol. Pak J Pharm Sci, 2005; 18(1):49.

Zhang Y, Law Y, Chakrabarti S. Physical properties and compact analysis of commonly used direct compression binders. AAPS PharmSciTech, 2003; 4(4):489-99.

How to cite this article:

Shetu AA, Sharmin S, Rony SR, Moni F, Samaddar PR, Sohrab

MH. Formulation and pharmacopoeial quality evaluation of ketorolac tromethamine IR tablet and comparison with marketed product. J Appl Pharm Sci, 2019; 9(05):082-087. 